\title{
Crafting a Successful Manuscript: Lessons from 131 Reviews
}

\author{
Steven G. Rogelberg • Marisa Adelman • \\ David Askay
}

Published online: 24 May 2009

(C) Springer Science+Business Media, LLC 2009

Having good data is simply not enough to assure publication in a high quality academic journal. The data must be sold, justified, described, and packaged in a compelling way. In this paper, we focus on how to prepare a quality manuscript. To do so, we content analyzed reviewer comments from nearly 100 manuscripts that were submitted to the Journal of Business and Psychology over a 4-month time period (November 2008-April 2009). This yielded 131 reviews. The goal was to identify areas of concern commonly expressed by manuscript reviewers. By doing so, it is our hope that we can better educate authors on the key elements of a successful manuscript, increase manuscript impact, and in general help data reach their potential.

The reviews were analyzed and common themes were identified. Illustrative comments were provided under each theme listed below. The themes were then organized into the following categories: (1) introduction section, (2) methods and results section, (3) discussion section, and (4) writing. It is important to note that not all of the themes and illustrative comments are universal-some may be more applicable to particular research designs and approaches (e.g., quantitative versus qualitative designs).

\section{Introduction Section}

Reviewers frequently expressed concerns about theoretical or conceptual rationale, clarity of research purpose, extent

All authors have contributed equally to this manuscript.

S. G. Rogelberg $(\bowtie) \cdot$ M. Adelman · D. Askay

University of North Carolina Charlotte, 9201 University City

Boulevard, Charlotte, NC 28223-0001, USA

e-mail: sgrogelb@uncc.edu of research contribution, and the content and/or structure of the literature review.

Conceptual and/or theoretical rationale:

- It is unclear why the particular variables were selected.

- The model is poorly specified or explained.

- Need to explain why particular variables were chosen as mediators/moderators.

- Missing variable concerns: need to consider other constructs that may be relevant to the model.

- Lacking theory behind focal constructs and relationships.

- Theories are discussed, but not effectively used as the framework for the research.

- Arguments are unclear, inconsistent, and not always compelling.

- Lack of connection between the model, the hypotheses, and the title.

Purpose/contribution of study:

- Title and abstract misrepresent the content of the manuscript.

- Need to clearly state the purpose and contribution of the study - do this early in the paper.

- Need to articulate what this study adds to the extant literature.

- Explain how this is more than a replication study.

- Need to highlight/emphasize the novel contribution of the study.

Proposed relationships/hypotheses:

- Some of the hypotheses seem trivial/it is unclear how the proposed relationships add to the literature.

- Need to more clearly state the direction of the proposed relationships. 
- Hypotheses/research questions are not clearly stated.

- Terms and constructs need to be clearly defined.

Redundancies/lack of conciseness:

- Introduction section is very long and redundant.

- Need to revise for clarity and conciseness.

- Methodological issues (e.g., specifics of the sample, measurement details) should generally be saved for the Methods section.

Literature review:

- Need to better integrate extant research with the aims of the present study instead of merely reviewing the literature.

- Incorporate a broad range of literature instead of relying extensively on recent, unpublished work.

- Need to mention recent review articles and recent controversies on your topic.

- Cited literature is misrepresented.

- Large amount of recent literature is missing.

- Extant literature is poorly integrated with present study.

- Cited literature is severely dated; recent studies are missing.

Some representative comments illustrating the above themes

"My main concern about this manuscript is that it is an empirical investigation without any specific a priori hypotheses."

"The Introduction, though useful, is a bit long for the paper."

"The literature review is generally excellent but has several shortcomings that undermine its clarity and make the reader question the relevance of this study."

"The contribution of Hypothesis 1, which deals with _ is weak. That is, the literature review provided by the authors (including their discussion of metaanalytic evidence) seems to demonstrate convincingly that are likely to be more related to than to _. Therefore, it is unclear how this hypothesis adds to the literature."

"While I appreciate the author's attempts to be thorough in their literature review, I think the manuscript would benefit from efforts to tighten up the introduction and literature review and make the stated arguments more concise."

"At several points in the manuscript, the authors make very strong statements without providing sufficient supporting references to empirical research backing up these claims. I would suggest toning these statements down or providing additional references to support these assertions."

"The model, as presented, is primarily heuristic. That is, the model is not tested in its entirety, but is instead used as a guiding framework. This is not a problem in and of itself. However, the authors, both in their choice to title the paper '___ and in their presentation of the model in the text, give it a centrality that it may not deserve."

"When reading the introduction, I was struck by the obviously interesting nature of the topic, the differing approaches used in past research, and the brevity with which all this was presented. At some points I would have appreciated a bit more theoretical background and explanation."

"The introduction of the paper delves immediately into the specific research scenario. I would like to see the author(s) spend a paragraph or two setting up the context of the research and discussing what has motivated the research. Why is this an important problem? Before getting into the conceptual model for the paper, I would like to see a clear statement of the purpose of this research."

"The authors do a nice job of identifying an area of research that deserves more research attention:

The authors address this issue with an impressive sample. However, as currently conceptualized, analyzed, and presented, this manuscript does not add to our understanding of

"My biggest critique is regarding the alignment of stated purpose with the actual work the paper puts forth."

\section{Methods and Results}

Reviewers frequently raised concerns about study measures, sampling strategies, the extent of methodological information presented, appropriateness of analyses, reporting of analyses, and common method bias issues.

Measurement:

- Need to provide sample items (if not all items) for each measure.

- Indicate the scale of the measurement.

- Describe how scales were scored and composites generated.

- Clearly define the variables/measures and identify how they effectively operationalize the study variables.

- Provide reliability and validity data for all measures.

- Need to report descriptive statistics for the measures.

- Assess discriminant validity using an exploratory factor analysis to show that all scale items adequately loaded onto their respective factors without problematic crossloadings. 
- CFA should be conducted on all items from each measure-do not run separate factor analyses for each scale, if possible.

\section{Sample/sampling strategy:}

- Need a better explanation of how participants were recruited, when and where they were surveyed, and which participants completed which measures.

- It is difficult to assess the appropriateness of the analyses and meaningfulness of the results because detailed information about the sample and procedure are not provided.

- Need discussion of how subjects were assigned to experimental conditions.

- Interpretation of the results is limited by the sampling strategy employed (convenience sampling) and the extremely small sample size.

- Very limited sample-serious range restriction on the criterion measure.

- Need to collect additional data with a broader sample.

- Discuss response rates and bias potential. Refer to Rogelberg and Stanton (2007).

Common method variance:

- Refer to Podsakoff et al. (2003) and Spector (1994, 2006).

- Common method bias issues should be considered in the design of the study and discussed.

- Language is too strong surrounding minimization of common method variance-effects were reduced, not eliminated.

General analytic issues:

- Theory should guide your analyses.

- Need to explain rationale behind chosen analyses, if not obvious (e.g., why an EFA was conducted instead of a CFA; see Bryant and Yarnold 2000; Fabrigar et al. 1999; Thompson 2007 for discussion).

- Effect size indicators are needed.

- Avoid over-analyzing the data, as "significant" results may be found due to chance.

- Individual-level analysis ignores the possibility that the groups in which members are nested influence their ratings - consider the need for HLM (see Ilies et al. 2009; Raudenbush and Bryk 2002).

- Your HLM analyses are problematic (see Bliese 2002; Hofmann et al. 2000).

- Make sure that the model being tested is consistent with the hypothesized relationships.

- Regression: report all betas in the table; consider plotting simple slopes; use proper language when describing regression techniques (e.g., regressed criterion on predictor variables).
- Use appropriate and most up-to-date procedures for testing moderation and mediation (e.g., Sobel test or bootstrapping). For a discussion of moderated regression analyses, see Aiken and West (1991) and Muller et al. (2005). For additional information on mediation, see James et al. (2006) and MacKinnon et al. (2002).

- Qualitative methods: need to report full list of interview questions; need to explain how qualitative coding scheme was developed; contextual information is needed (for additional information, see Denzin and Lincoln 2005; Miles and Huberman 1994; Willig 2001).

Reporting results:

- Include an explanation of the study procedure.

- Explain the standards for excluding data that were returned and subsequently not included in the analyses.

- Missing important information about the participants and procedure, specifically contextual factors related to the nature of the task.

- Display caution in over-interpreting null results.

- Results should be consistent with APA style guidelines.

- Need more detail and clarity: specifically state which results provide support for which hypotheses.

Language/tone of results:

- Avoid causal language when using a cross-sectional design.

- Avoid evaluative language; report findings without reference to what constitutes a "good" model.

- Do not use "marginally significant" and "marginally supported."

Some representative comments illustrating the above themes

"I had a number of concerns regarding how you measured your variables. Given that the measures are mostly ad hoc measures, you need to justify these more thoroughly."

"As it stands, especially with the regression analyses, there is little consistency across occupation which may be due to capitalization on chance. In fact, Table 3 only presents the significant results; you should present all results (significant or not)."

"I found the analyses difficult to follow because at least one of the figures referred to seemed to be missing. Similarly, the list of figures does not match the figures."

"While your hypothesis essentially proposes an interaction, your regression-analysis tests for two main-effects. A subsequent step should include the proposed interaction between 
"Significance is a binary variable: a particular result either is or is not statistically significant, and the field of applied psychology imposes a hurdle of $p<.05$ for this claim to be substantiated."

\section{Discussion}

Many reviewers noted problems with the structure of the discussion section, missing components, overgeneralization of results, and a lack of meaningful interpretation.

Discussion section style/structure:

- Be sure to discuss your findings, implications, limitations, and future research ideas.

- Open the discussion section with a brief review of the results (e.g., clearly and concisely articulate which of the hypothesized relationships were supported).

- Make sure the terms are consistent throughout your paper-do not start using different terminology in the discussion section.

- The discussion section is too short.

- The final paragraph in the paper needs to cohesively summarize the importance of the authors' work.

Interpretation of findings:

- Need to consider alternative explanations for findings.

- Acknowledge other potential mediators/variables and pose possibilities for future research.

- Avoid making statements in the discussion that are not supported by the methods and results.

- Answer the "so what" question-clearly articulate the knowledge gained as a result of the study and how this knowledge can be used.

- Need to link the results to extant literature-highlight the contribution of the present results above and beyond previous work.

Limitations and implications:

- Address limitations due to sample size and composition.

- Applied implications have no foundation in data or design.

- Include a discussion of the practical implications.

- Practical application of results needs to be better explained.

Some representative comments illustrating the above themes

"The authors made a strong start in their discussion of the findings by underlining the contributions of their study (instead of a summary of findings, as is often the case).
However, I felt that they relied perhaps somewhat too much on speculation when addressing 'unexpected' findings."

"The theoretical implications of the results need to be explored in more depth, and the authors need to be careful not to make claims unsupported by their results. One such example can be found ...."

"The authors should exercise caution in suggesting causal inferences based on their data; for example ...."

"I would like to see much more discussion on what the findings mean to practitioners and researchers. What do the findings suggest we do differently? What are the implications of these findings? I'd like to see the manuscript go deeper into the importance and implication of the findings."

"I would like to see the discussion go into greater detail about the meaning of the results and the implications. Why were the expected effects found only for ? Is this pattern of findings consistent with what was found in other studies? Tie this back to the literature. What does this mean for __ in other settings? Can you generalize the results? I would like to see a much more extensive discussion of these issues than what is currently presented."

\section{Writing}

Reviewers frequently expressed concern about the overall quality of the writing, particularly noting grammatical and spelling errors, and errors in APA style. In addition, reviewers often commented on a lack of clarity in the overall manuscript.

Editing and grammar:

- Poor grammar.

- Spelling errors.

- Problems with omitted words.

- Confused verb tenses.

- Need to use an active voice.

- Data "were" not "was."

- Use more paragraphs.

- Avoid grandiose over-statements; write in a scholarly manner.

- Avoid the use of judgmental or evaluative statements.

- Concerns relating to APA style.

- Writing issues were more common in manuscripts submitted by non-native English speakers; indicates a need for editing by a native English speaker.

- Proofread, proofread, proofread.

Manuscript lacks clarity:

- Reads like a thesis-need to be more concise and clear in logic. 
- Need to clearly define focal constructs and terms.

- Heavy use of acronyms hinders comprehension.

- Be consistent in use of terms-using terms interchangeably hinders comprehension.

- The manuscript does not flow well; the logic behind the arguments is disjointed.

- Additional headings would enhance the clarity of the manuscript.

Some representative comments illustrating the above themes

"The manuscript is very well written and well-organized, which made it a pleasure to read."

"In general, I would suggest going through the manuscript very carefully to check for proper grammar as there are a number of instances of grammatical issues."

"This manuscript would benefit greatly from the editorial services of an expert in the English language. I highly recommend the author(s) consult their university's English department for any services for editing English documents."

"There are a number of errors in writing I would ask the author(s) to address."

\section{Conclusion}

This paper is designed to help authors become better aware of the types of issues and concerns reviewers typically raise in their reviews. We hope that authors will take the above concerns into consideration prior to submitting a manuscript for publication. Doing so not only should result in greater success for authors, but will provide good data more of an opportunity to have a meaningful impact on organizational science and practice.

\section{References}

Aiken, L. S., \& West, S. G. (1991). Multiple regression: Testing and interpreting interactions. Newbury Park, CA: Sage.

Bliese, P. D. (2002). Multilevel random coefficient modeling in organizational research: Examples using SAS and S-PLUS. In F.
Drasgow \& N. Schmitt (Eds.), Modeling in organizational research: Measuring and analyzing behavior in organizations (pp. 401-445). San Francisco, CA: Jossey-Bass, Inc.

Bryant, F. B., \& Yarnold, P. R. (2000). Principal-components analysis and exploratory and confirmatory factor analysis. In L. G. Grimm \& P. R. Yarnold (Eds.), Reading and understanding multivariate statistics (pp. 99-136). Washington, DC: American Psychological Association.

Denzin, N. K., \& Lincoln, Y. S. (2005). Handbook of qualitative research (3rd ed.). Thousand Oaks, CA: Sage.

Fabrigar, L. R., Webener, D. T., MacCallum, R. C., \& Strahan, E. J. (1999). Evaluating the use of exploratory factor analysis in psychological research. Psychological Methods, 4, 272-299.

Hofmann, D., Griffin, M., \& Gavin, M. (2000). The application of hierarchical linear modeling to organizational research. In K. J. Klein \& S. W. J. Kozlowski (Eds.), Multilevel theory, research and methods in organizations (pp. 467-512). San Francisco, CA: Jossey-Bass.

Ilies, R., Wilson, K. S., \& Wagner, D. T. (2009). The spillover of daily job satisfaction onto employees' family lives: The facilitating role of work-family integration. The Academy of Management Journal (AMJ), 52(1), 87-102.

James, L. R., Mulaik, S. A., \& Brett, J. M. (2006). A tale of two methods. Organizational Research Methods, 9, 233-244.

MacKinnon, D. P., Lockwood, C. M., Hoffman, J. M., West, S. G., \& Sheets, V. (2002). A comparison of methods to test mediation and other intervening variable effects. Psychological Methods, 7, 83-104.

Miles, M. B., \& Huberman, A. M. (1994). Qualitative data analysis: An expanded sourcebook (2.th ed.). Thousand Oaks, CA: Sage.

Muller, D., Judd, C. M., \& Yzerbyt, V. Y. (2005). When moderation is mediated and mediation is moderated. Journal of Personality and Social Psychology, 89, 852-863.

Podsakoff, P. M., MacKenzie, S. B., Lee, J. Y., \& Podsakoff, N. P. (2003). Common method biases in behavioral research: A critical review of the literature and recommended remedies. Journal of Applied Psychology, 88(5), 879-903.

Raudenbush, S. W., \& Bryk, A. S. (2002). Hierarchical linear models: Applications and data analysis methods. Sage Publications Inc.

Rogelberg, S. G., \& Stanton, J. M. (2007). Introduction: Understanding and dealing with organizational survey nonresponse. Organizational Research Methods, 10(2), 195-209.

Spector, P. E. (1994). Using self-report questionnaires in OB research: A comment on the use of a controversial method. Journal of Organizational Behavior, 15(5), 385-392.

Spector, P. E. (2006). Method variance in organizational research: Truth or urban legend? Organizational Research Methods, 9(2), 221.

Thompson, B. (2007). Exploratory and confirmatory factor analysis: Understanding concepts and applications. Applied Psychological Measurement, 31(3), 245-248.

Willig, C. (2001). Introducing qualitative research in psychology. Buckingham, PA: Open University Press. 